Universidad de Lima

Facultad de Comunicación

Carrera de Comunicación

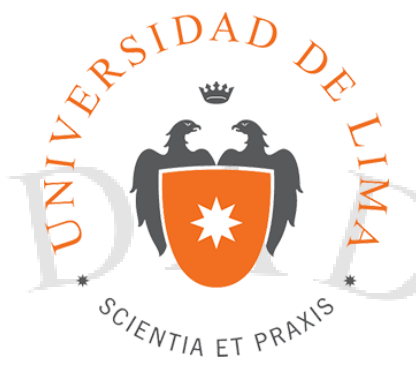

\title{
PORTAL INFORMATIVO TURÍSTICO \\ PLANEA PERÚ
}

Trabajo de Suficiencia Profesional para optar el Título Profesional de Licenciado en

Comunicación

\section{Angela Beatriz Arce Gamarra \\ Código 20090059}

\section{Asesor}

Eduardo Lavado

$$
\text { Lima - Perú }
$$

18 de septiembre del 2018 


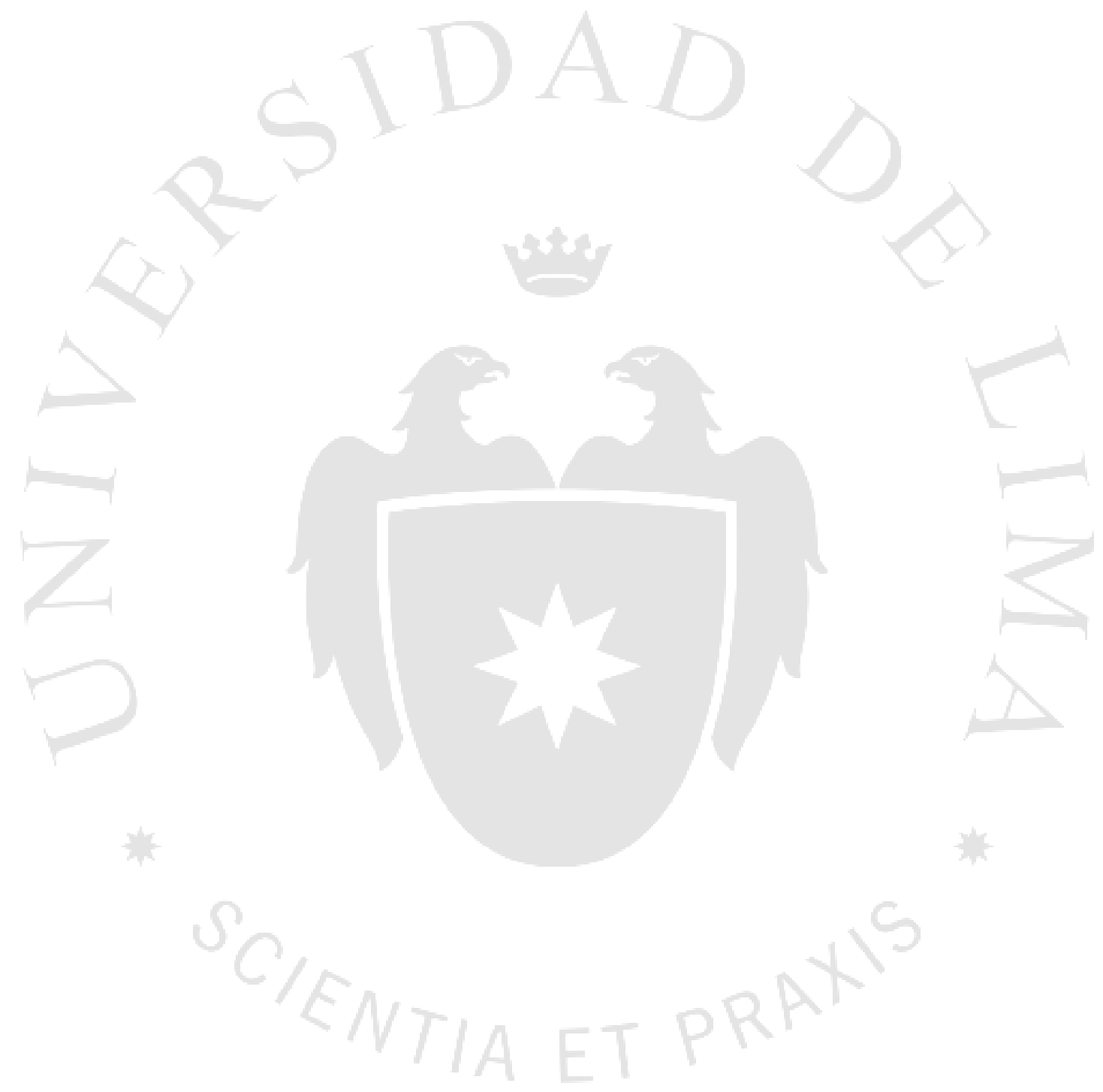




\section{PORTAL INFORMATIVO TURÍSTICO PLANEA PERÚ}




\section{ÍNDICE}

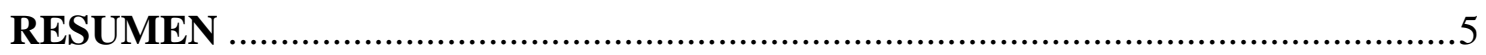

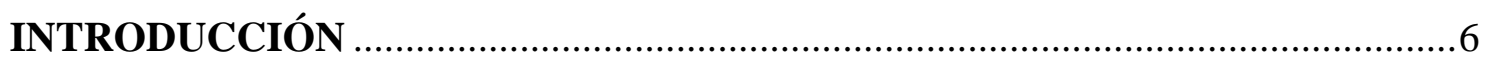

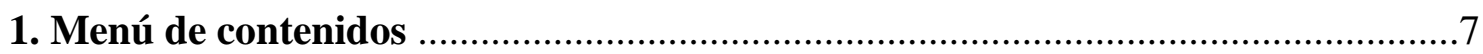

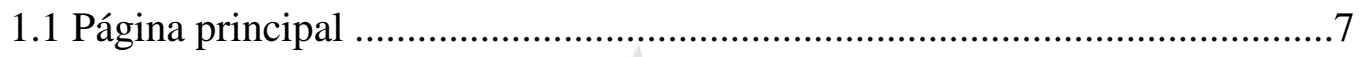

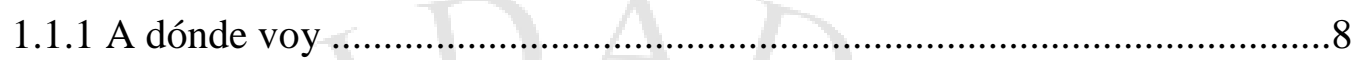

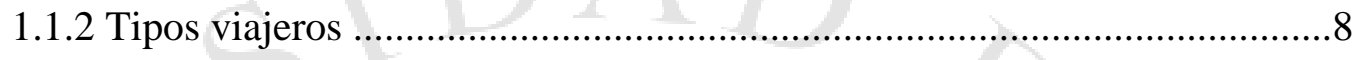

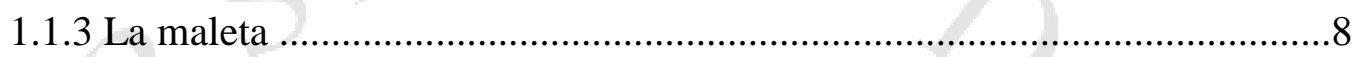

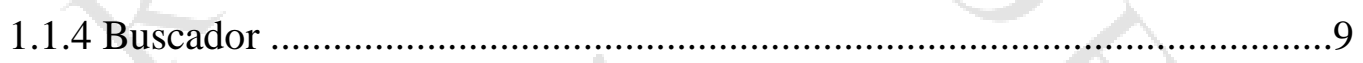

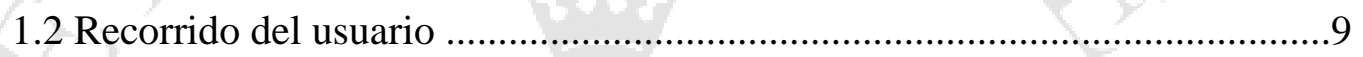

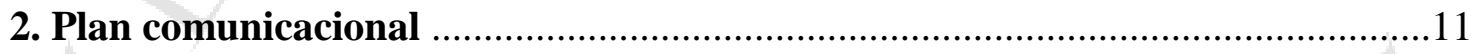

2.1 Flujo de contenido web ........................................................................ 11

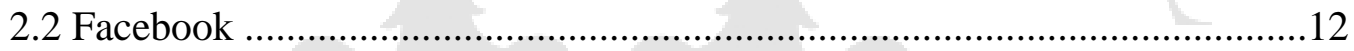

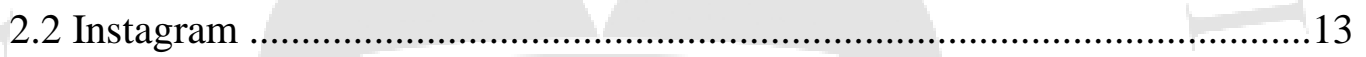

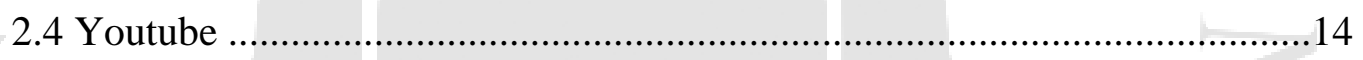

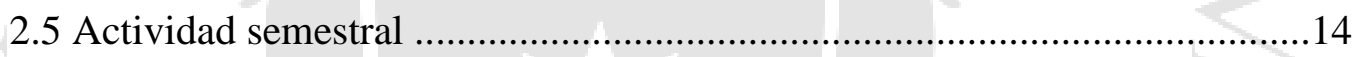

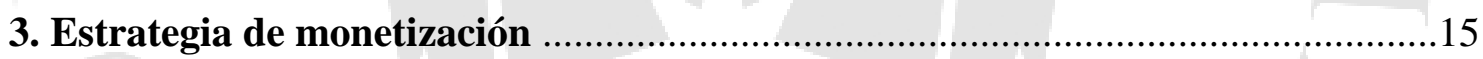

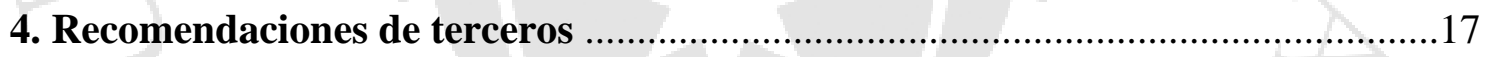

4.1 Sugerencias en la página principal .......................................................... 17

4.2 Sugerencias en la parte inferior de la página principal ..............................18

4.3 Sugerencias en la página de propuestas .....................................................18

4.4 Sugerencias en la ventana de descripción detallada ...................................18

4.5 Sugerencias en la página final .............................................................. 18

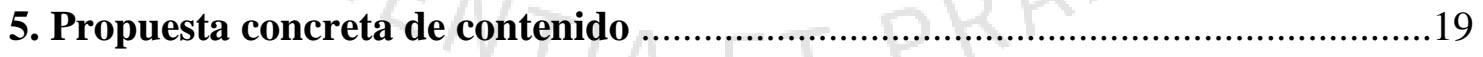

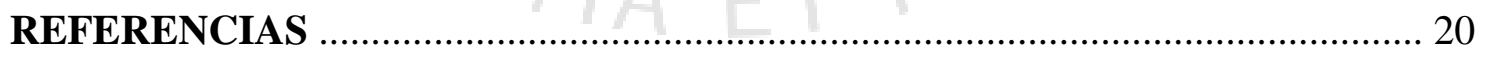

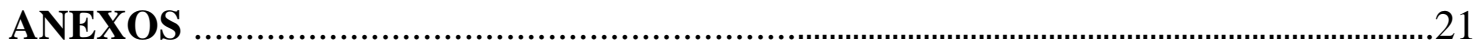




\section{RESUMEN}

El portal turístico informativo Planea Perú busca, principalmente, brindar toda la información disponible sobre el destino deseado y ofrecer la mayor cantidad de recomendaciones posibles. Es una herramienta que ayuda a organizar un viaje de manera entretenida y ordenada. Con un variado menú de contenidos, constantemente actualizado, este sitio web plantea que no puedes quedarte sin experimentar un lugar, una comida o una actividad solo por no saber que existe. Gracias a su propuesta diferencial, Planea Perú te permite llevar a todos lados tu plan de viaje, con cada elemento que has investigado y seleccionado. Además, debido a su contundente presencia en las redes sociales más usadas actualmente, la información podrá llegar a los usuarios por distintos medios, así como también le permitirá interactuar con las diversas funciones y piezas gráficas. Bienvenido.

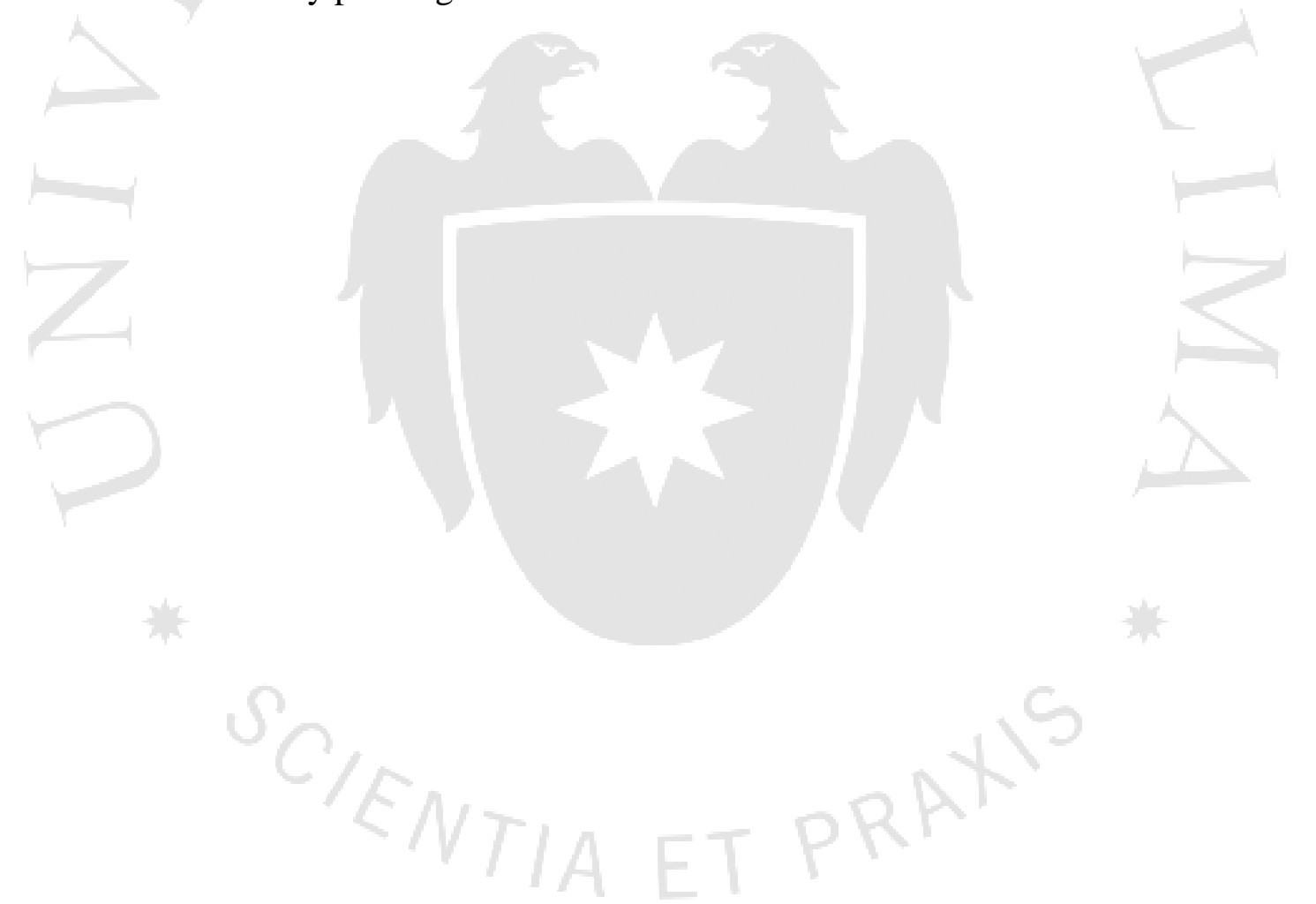




\section{INTRODUCCIÓN}

Planea Perú parte de las ganas de facilitar la experiencia de planificar un viaje, sin perderse de nada. Frente a la realidad de que cuando uno quiere realizar una excursión e investigar al respecto debe abrir muchísimas pestañas de Internet, Planea Perú simplifica todo en un solo sitio web. Este ofrece la posibilidad de definir a dónde podría querer ir el usuario indeciso, de averiguar cuándo es la mejor temporada, de encontrar consejos útiles y, sobre todo, de planificar tus días de viaje al máximo. ¿Cómo? A través de un sencillo y amigable portal informativo que proporcionará todo aquello que deseas saber sobre un destino. Es, al fin y al cabo, una herramienta que ayuda a organizar un viaje de manera entretenida y ordenada.

El logo de Planea Perú (Anexo 1) es fácil de ubicar, justamente porque tiene el ícono de ubicación de GPS que muchos conocemos por nuestros celulares. La versión simplificada para redes es el solo ícono (Anexo 2). Además, se utiliza el rojo porque impacta cuando es bien combinado y porque es uno de los colores emblema del Perú. El anaranjado es otro color principal en el portal, pues, a pesar de ser un poco ignorado, este tono le da vida. Finalmente, el negro y los grises le dan una sensación de unidad a todo el portal.

Atrás quedaron los días en los que llegábamos a un lugar fuera de temporada o aquellos en los que debíamos partir antes de que empezaran las festividades locales. No pierdas la oportunidad de sacarle el jugo a tu experiencia y conoce el Perú a tu manera. 


\section{MENÚ DE CONTENIDOS}

\section{La experiencia Planea Perú}

\subsection{Página principal}

Apenas el usuario ingresa a la dirección www.planeaperu.com, lo primero que le llamará la atención es la vistosa foto (Anexo 3), que, cada cinco segundos, se deslizará para dejar aparecer otras cinco, igual de llamativas. Arriba de la foto estará la franja del menú principal, que inicia con el logo de Planea Perú, seguido de la pestaña de presentación "Acerca de nosotros" (Anexo 4), y de las otras dos: "A dónde voy" y “Tips viajeros". La franja cambia de color en "Tu maleta", uno de los elementos diferenciales de este portal . A la derecha, habrá pequeños íconos con los vínculos a las respectivas redes sociales de Planea Perú, la opción para iniciar sesión - puede ser con Google y Facebook - y la pestaña para cambiar el idioma entre español, inglés y quechua. El objetivo es que más adelante se incorporen otras lenguas peruanas, como aimara, asháninka y shipibo, que son algunas de las que ya tienen alfabeto oficial.

Sobre la esquina inferior derecha de la foto principal, estará el buscador para poder empezar a planificar el viaje a cualquier lugar del Perú. Esta sección, titulada "Mi viaje”, solicitará al usuario información básica (obligatoria) y específica (opcional) para poder ofrecer las propuestas más precisas de acuerdo a sus preferencias. El recorrido del usuario con el buscador se explicará más adelante.

Más abajo, se verá un área de actividades que estén en tendencia, llamada "Populares". Inicialmente se verán las imágenes de cada recuadro con transparencia roja y solo el título; al pasar el cursor por cada una, esta mostrará todos sus colores y la descripción correspondiente. Al menos dos de las tres opciones serán monetizadas. Es decir, ahí habrá distintas notas informativas y divertidas acerca de hoteles que deseen promocionarse, actividades municipales que los gobiernos regionales quieran dar a conocer, ofertas de empresas privadas relacionadas al sector, novedades turísticas en distintos lugares del Perú y más. Por ejemplo, en la maqueta del portal adjunta a este proyecto (Anexo 5), se promociona la actividad del canotaje en una nota informativa, un hospedaje en la selva en una nota comparativa y tres festividades —el carnaval de Cajamarca y las fiestas de la Virgen de la Candelaria en Puno y de la Virgen de Paucartambo en Cusco- en un video corto. 
En la parte inferior, habrá una galería de fotos que pertenecerán al perfil de Instagram de Planea Perú (Anexo 6). Además, se instará a los visitantes del portal a subir fotos de sus viajes por el país, utilizando el hashtag \#planeaPeru, lo que habilitará la opción de rebotarlas en el perfil del portal y, por lo tanto, de aparecer en esta sección de la página principal.

\subsubsection{A dónde voy}

Esta pestaña parte de la premisa de que uno a veces quiere viajar pero no sabe a dónde. Se aplica mucho a las escapadas de fin de semana y a las vacaciones en fechas específicas. Aquí las opciones que se ofrecerán dependen mucho del mood del usuario (Anexo 7). Por eso, se han seleccionado las siguientes: De juerga (destinos con mucha actividad nocturna), Con mis bendiciones (destinos orientados a actividades familiares), Para exorcizarme el estrés (destinos que prometan relajo), Para culturizarme (destinos con relevancia histórica peruana y literaria), Para aportar mi granito de arena (destinos que ofrecen voluntariados en conjunto con $\mathrm{ONG}$ ), y el calendario de festividades. Este último incluirá una lista detallada de las celebraciones que se realizan en todo el país (Anexo 8).

\subsubsection{Tips viajeros}

Esta pestaña se centrará en ofrecer recomendaciones de viajero a viajero. Estarán numeradas y la mayoría serán anónimas — redactadas por el personal de la página—; sin embargo, de vez en cuando se invitará a conductores de programas de viaje, actores, periodistas, escritores, influencers y otros personajes reconocidos para que den los consejos según sus experiencias. Asimismo, se recogerán tips de los seguidores de Instagram que respondan al llamado y se les mencionará. Aquí la idea es que las notas o videos sean puntuales con las recomendaciones que ofrecen (Anexo 9).

\subsubsection{La maleta}

Bajo la premisa de que el usuario ya conoce que en los sitios web de compra uno “agrega al carrito" lo que le interesa adquirir, se presenta su equivalente: la maleta. Esta pestaña, uno de los principales ejes diferenciales del portal, es a donde van a parar todas las propuestas que el usuario seleccione para luego organizarlas en un calendario con las fechas que elija viajar. Más adelante, en el recorrido del usuario, se detallará el proceso. 


\subsubsection{Buscador}

Esta sección es una de las principales del portal. Permite que, de acuerdo a la información que el usuario brinde, Planea Perú pueda dar las mejores propuestas en base a los gustos específicos para una experiencia en particular. Por eso, el buscador se llama "Mi viaje". Los recuadros obligatorios para llenar son las fechas en las que inicia y termina el viaje, así como el destino, que será un espacio para redactar con la opción de autocompletar, pues puedes colocar una región, una ciudad o un distrito específico.

Los recuadros más específicos serán opcionales, pues forman parte de lo que se suele llamar "búsqueda avanzada"; sin embargo, siempre estarán a la vista para instar al usuario a llenarlos. Las categorías son cantidad de viajeros, presupuesto bajo, medio o alto, rango de edad, clima y tipo de actividad (Anexo 10). Esta última se despliega en varias opciones: adrenalina, parejas, juerga, con patas, ecofriendly, LGBTQ, rural comunitario, petfriendly, familiar y voluntariado.

\subsection{Recorrido del usuario}

Después de elegir todas las opciones del buscador, aparecerá una nueva página con las propuestas planteadas por Planea Perú (Anexo 11). Habrá una barra sencilla arriba de todas las propuestas, donde se podrá cambiar las fechas de viaje y la ciudad. Esto con la intención de que el usuario no tenga que volver a la página principal para llevar a cabo esa simple operación.

Cada opción tendrá dos íconos pequeños: en la esquina superior izquierda el tipo de propuesta (aventura, fiesta, lugar, comida, hospedaje, entre otros) y en la esquina superior derecha el símbolo + , para poder agregarlo a la maleta. Esto permite que el usuario identifique con facilidad qué le está proponiendo Planea Perú para su viaje. A la izquierda habrá una barra con una lista de filtros para ajustar aún mejor las opciones y se podrá cambiar lo que se marcó en la búsqueda inicial. Si se desea más información sobre una de las propuestas, bastará con darle un clic para que aparezca una ventana con transparencia donde se podrá leer una descripción más detallada al respecto (Anexo 12), sin salir de la página de propuestas. En la parte inferior de esa misma ventana, el portal ofrecerá otras tres opciones relacionadas (Anexo 13). Las propuestas que impliquen establecimientos estarán vinculadas a Tripadvisor y Foursquare, para garantizar buen servicio. 
Una vez que se seleccione todo lo deseado, se dará clic a la maleta para ir al calendario personalizado con las fechas indicadas para el viaje. En ese espacio, el usuario, si recién está entrando por primera vez, ya podrá iniciar sesión directa, con Google o con Facebook. No es necesario iniciar sesión para poder utilizar el planner, pero al hacerlo no solo se podrá exportar en PDF el resultado final, sino sincronizar con Google Calendar, y activar distintas opciones que se describirán más adelante.

En esta página, a la izquierda se verán todas las opciones seleccionadas y a la derecha, el calendario (Anexo 14). El usuario deberá arrastrar el destino o actividad de la izquierda hacia el día deseado. Una vez colocado, ese día bloqueará las actividades similares que ya sean irrealizables. De esta manera, se irá organizando el día a día. Cuando haya algún cruce, el calendario simplemente no dejará que se incluya la actividad seleccionada en el día previsto.

Al terminar, se podrá dar clic a la opción presupuesto aproximado, que calculará el total de dinero que se gastará basado en la selección de actividades y la cantidad de días. Ya cuando esté todo listo se podrá exportar como PDF y enviar al correo electrónico indicado al iniciar sesión. Como el usuario ya se habrá registrado para ese momento, tendrá habilitada la opción de activar la "alerta de imprevistos", que, frente a cualquier suceso que pueda perjudicar el plan viajero - se cae un puente, cierra un lugar o hay huelga, por ejemplo- - enviará un mensaje de texto (Anexo 15) o, si es que tiene la app, se activará la notificación.

\subsection{Funciones exclusivas de la app}

La app de Planea Perú tendrá el mismo objetivo que el portal: ayudar a planificar un viaje aprovechando todo lo disponible al máximo (Anexo 16). Además, el usuario podrá activar diferentes notificaciones para los viajeros más olvidadizos. Aparte de los anuncios más básicos, que señalan lo ya elegido en el planificador, tendrá la opción de que le avise los horarios de comida con un "Llegó la hora del combate. Ubica los restaurantes más cercanos". De esta manera, se habilitará el GPS del celular y se ofrecerán distintas propuestas. El usuario también podrá activar las notificaciones del pronóstico del clima, función que podrá ser enviada al mail días antes si así lo desea. Al finalizar el viaje, se activará la opción de que el usuario envíe sus comentarios y recomendaciones sobre los lugares para ir recopilando una base de datos que podrán luego plasmarse en tips viajeros. 


\section{PLAN COMUNICACIONAL Viajar en los tiempos del engagement}

El eje principal de la comunicación del portal es el contenido de valor, debido a que se busca lograr posicionamiento dentro de la audiencia. No se trata solo de instarlos a entrar al portal, sino de que se familiaricen con el tema, que se entretengan y que creen un vínculo con las redes de Planea Perú.

\subsection{Flujo de contenidos del portal}

Estos son los elementos del portal que cambiarán cada cierto tiempo:

- Fotos de portada: Las cinco fotos de la página principal - que rotarán entre ellas cada cinco segundos - se renovarán una vez al mes. No obstante, ese cambio no será de todas en simultáneo. Cuatro tendrán fija una semana del mes y la quinta variará de acuerdo a las necesidades del portal, por ejemplo, para anunciar un video nuevo.

- Tips viajeros: Esta sección sencilla y entretenida tendrá contenido nuevo los jueves de cada semana. Sin embargo, en caso haya ya mucho contenido planteado para alguna semana determinada, se podrá saltar a la siguiente para no sobrecargar a los usuarios.

- Populares: Al ser esta una sección monetizada en su mayoría, la duración oscilará entre mínimo una semana y máximo un mes. Como será temática variada - a veces notas exclusivamente informativas sobre un lugar o una actividad, a veces comparaciones entre una actividad y otra (evitando el conflicto entre los anunciantes), a veces galerías fotográficas-, la única condición será que no se crucen los contenidos similares.

- Videos: Se publicará un video cada dos semanas porque requieren más tiempo de producción para mantener la calidad del contenido. Se lanzarán los domingos (uno sí, uno no), por el gran tráfico de usuarios que navega por ocio ese día.

- Destacados de Instagram: Los lunes de cada semana se actualizarán las fotos de la última sección de la página principal, es decir, la selección de fotos de seguidores de Instagram que utilizaron el hashtag. Este será el día ideal, pues la mayoría de publicaciones - y de viajes cortos - son durante el fin de semana.

Para promocionar los tips viajeros, la sección de Populares, los videos nuevos y los cambios en la zona de destacados, se utilizarán las siguientes redes sociales detalladas. 


\subsection{Facebook}

Esta red social es, sin lugar a dudas, la más estable para empresas. Debido al gran tránsito que tienen los usuarios y a que, incluso los más renuentes ya están empezando a sucumbir a tener perfil, realizar una publicación en Facebook y pautearla con una adecuada segmentación puede ocasionar que, como marca, llegues a muchas personas según tu público objetivo. Por eso, en su fase inicial, la fanpage de Planea Perú (Anexo 17) publicará dos veces por semana - una con pauta y otra orgánica-.

La línea temática de las publicaciones hará énfasis en curiosidades y noticias de interés relacionadas con el acto de viajar (Anexo 18). Asimismo, se realizará fotogalerías de destinos novedosos y posts de consejos viajeros en los jueves de tips (Anexo 19). No faltarán los videos, pues se publicarán sneak peaks de los que se subirán a la página y, además, habrá entrevistas ocasionales a personajes reconocidos que estén relacionados con viajes, ya sea de la televisión, de la radio o de Youtube (como Sonaly Tuesta, Gonzalo Torres, Misias pero viajeras). De esta forma, habrá un rebote orgánico y se llegará a más seguidores. Como toda buena fanpage activa, se lanzarán concursos mensualmente en conjunto con agencias de viaje, pero también con marcas de emprendedores peruanos para apoyar el crecimiento y la formalización de creativos productos nacionales (Anexo 20).

También se utilizará la fanpage para encuestar y examinar al público objetivo antes de lanzar nuevas secciones. Por ejemplo, si Planea Perú está considerando habilitar una opción para que el usuario pueda contactarse con gente del lugar a donde va a ir, primero expondrá la idea para recoger opiniones al respecto.

Para monetizar y aprovechar el nicho de seguidores que tendrá la fanpage, se ofrecerá a las empresas aliadas $-\mathrm{y}$ a las que deseen - espacios para promocionar sus ofertas relacionadas a viajes, por ejemplo, que durante el fin de semana habrá $15 \%$ de descuento o que una marca de ropa de deporte de aventura ha lanzado una nueva colección. También se tendrá la política de recibir propuestas temáticas de parte de las empresas para fortalecer las alianzas estratégicas. Esto se desarrollará más adelante en la sección de estrategia de monetización.

Para promover la interacción, cada publicación tendrá un call to action, ya sea para ingresar al portal, para etiquetar a algún amigo, para comentar la foto o alguna otra acción compatible con el tema propuesto. Asimismo, se tendrá como consigna responder siempre lo antes posible todos los mensajes que lleguen. 
Con el objetivo de facilitar la acción en Facebook, se elaborará una semana tipo como la presentada a continuación. Sin embargo, como ya se mencionó antes, no todas las semanas habrá cinco publicaciones, la idea es ir rotando y tener siempre dos a la semana.

\begin{tabular}{|c|c|c|c|c|c|}
\hline & \multicolumn{5}{|c|}{ Semana tipo } \\
\hline Temática & $\begin{array}{c}\text { Curiosidad } \\
\text { o trivia }\end{array}$ & $\begin{array}{c}\text { Entrevista a } \\
\text { viajero }\end{array}$ & $\begin{array}{c}\text { Destino } \\
\text { novedoso }\end{array}$ & Consejos & $\begin{array}{c}\text { Anuncio de } \\
\text { aliado }\end{array}$ \\
\hline Hashtag & $\begin{array}{c}\text { \#SabíasQue } \\
\text { \#YalaNola }\end{array}$ & $\begin{array}{c}\text { \#TuViajero } \\
\text { Favorito }\end{array}$ & $\begin{array}{c}\text { \#Tendencia } \\
\text { Viajera }\end{array}$ & \#JuevesDeTips & $\begin{array}{c}\text { \#ViernesDe } \\
\text { Ofertón }\end{array}$ \\
\hline Formato & Imagen & Video & Fotogalería & Imagen & Imagen \\
\hline Call to & $\begin{array}{c}\text { Reacciona } \\
\text { :O si no } \\
\text { sabías y }<3 \\
\text { si yala. }\end{array}$ & $\begin{array}{c}\text { Menciona en } \\
\text { los } \\
\text { comentarios a } \\
\text { quién quieres } \\
\text { que } \\
\text { entrevistemos. }\end{array}$ & $\begin{array}{c}\text { Sube tu foto de } \\
\text { este destino en } \\
\text { los } \\
\text { comentarios. }\end{array}$ & $\begin{array}{c}\text { Ingresa a la } \\
\text { web para saber } \\
\text { más. }\end{array}$ & $\begin{array}{c}\text { Etiqueta a } \\
\text { quien quieres } \\
\text { que te compre } \\
\text { esto. }\end{array}$ \\
\hline
\end{tabular}

\subsection{Instagram}

Al ser una de las redes sociales que más ha crecido en los últimos años, se hará énfasis en su contenido, que se caracterizará por ser juguetón, divertido y fresco; asimismo, se promoverá la interacción con diversas secciones en las historias, que serán entre tres y cinco por día, para que el perfil se mantenga presente entre sus seguidores.

Respecto a las publicaciones, habrá fotos y videos del Perú. Este contenido estará muy cuidado visualmente para que pueda competir con los otros perfiles de viajes (Anexo 21). De acuerdo al calendario de festividades y aniversarios de las ciudades, se podrán establecer temáticas mensuales. Asimismo, se rebotarán algunas fotos de los usuarios que utilicen el hashtag \#planeaPerú, para aumentar las visitas y los seguidores, al estilo de \#igersPerú. Al menos una vez al mes se realizarán concursos en alianza con empresas de viaje y que puedan ser ocasionalmente promovidos por influencers del mismo rubro. El equipo se deberá mantener al tanto de las tendencias para poder crear contenido compatible con Planea Perú.

Respecto a las historias, estarán como base las fotos y videos de viajes en todo el país con textos entretenidos (Anexo 22). A veces, estas fotos estarán acompañadas de 
preguntas y encuestas, para instar a los seguidores a que interactúen para publicar sus respuestas (Anexo 23). Las historias también servirán para anunciar nuevas publicaciones y para crear concursos cortos — afines a sus 24 horas de duración-, que ocasionalmente pueden estar ligados a las preguntas que se lanzarán (Anexo 24). Una vez a la semana se publicará la opción "Hazme una pregunta" para poder resolver las dudas viajeras de los seguidores.

En cuanto a las historias destacadas, aparecerán las siguientes secciones: plantillas — cuestionarios vacíos para que los seguidores puedan copiar, llenar y publicar en sus historias etiquetando a Planea Perú- (Anexo 25), tips viajeros - compilación de recomendaciones variadas y de las respuestas que daremos a las dudas que nos dejen(Anexo 26), minientrevistas — preguntas curiosas sobre viajes a influencers y otros famosos - (Anexo 27) y tutoriales de cómo utilizar el buscador del portal.

Habrá un monitoreo constante, no solo del hashtag, sino para que etiqueten a Planea Perú para poder "repostear" la historia del seguidor. Cuando ya haya más de 500 seguidores, se implementará la plantilla "Arma tu manchita" para que los usuarios que viajan solos encuentren quién va al mismo destino en los mismos días que ellos.

\subsection{Youtube}

Esta red social será de apoyo para Planea Perú, pues el objetivo no se centra solo en videos. La mayor ventaja será que funcionará como almacén de todo el contenido audiovisual que se publique en el portal.

\subsection{Actividad semestral de influencers}

Cada seis meses, Planea Perú organizará un viaje a algún destino nacional durante una semana al que invitará a diez influencers para que interactúen. El objetivo es entretenerlos y que el uso del hashtag y de las etiquetadas a las redes sociales del portal sea orgánico; para mayor confiabilidad, el contenido que suban debe ser muy natural. Solo se les dará algunas pautas y lo demás será organizar actividades para que ellos cuenten sus experiencias y compartan momentos agradables. 


\section{ESTRATEGIA DE MONETIZACIÓN Rentabilidad online del turismo}

Planea Perú, de acuerdo a la proyección de crecimiento, apunta a conseguir entre mil y tres mil visitantes diarios después de los primeros seis meses después del lanzamiento. Tomando en cuenta esa cantidad y teniendo como auspiciador a Canatur, las empresas del rubro no tardarán en interesarse en promocionarse en el portal. Por lo tanto, se podrá formar atractivas alianzas estratégicas.

Asimismo, si se tiene en cuenta la ley que prohíbe el uso de publicidad estatal en medios privados (El Comercio, 2018), PromPerú, que podría considerarse la competencia, queda limitado con su promoción. Esto ocasiona que se abra un espacio para nuevas propuestas como Planea Perú. En este sentido, las oportunidades son sólidas.

Es así que a las marcas que quieran anunciar, se les ofrecerá los siguientes espacios:

- Redacción de una nota informativa sobre sus productos o servicios, con enfoque periodístico para no caer en el "publicherry"; habrá distintas tarifas dependiendo del tiempo que quiera quedarse en la página principal (entre una semana y un mes).

- Aparición en una de las tres primeras propuestas de la página de resultados, cada vez que algún filtro coincida con su producto o servicio. En este caso, las tarifas serán mensuales y pueden extenderse hasta un año.

- Presencia en las barras de publicidad de la app, siempre que sean empresas relacionadas al rubro, a través de Google ads.

- Mención en los videos promocionales de las actividades populares de la temporada.

- Auspicio de video, con presencia del logo, sobre destinos que sean compatibles con lo que ofrece la empresa aliada.

Por otro lado, se llegará a acuerdos con los aliados estratégicos más grandes para que Planea Perú tenga su propio vínculo trackeado específico. Así, cada vez que un usuario efectúe una compra a la que ha llegado gracias al vínculo del portal, este recibirá una comisión. Por ejemplo, en alianza con un sitio web de alguna aerolínea, podemos habilitar el botón “¿Ya compraste tu pasaje?”. Esta modalidad, llamada “programa de 
afiliados", es bastante utilizada por influencers y se puede replicar con éxito en el portal, debido al interés que generará como oportunidad para diferentes marcas.

Además, las redes sociales de Planea Perú también serán un espacio donde se podrá auspiciar, pues la política del portal será estar siempre abierto a nuevas propuestas temáticas de parte de sus aliados, por lo que se podrán crear atractivos concursos, que impliquen beneficios para ambas empresas, así como un gran premio para el ganador.

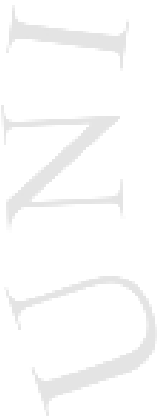




\section{RECOMENDACIONES DE TERCEROS}

El martes 12 de septiembre publiqué en mi perfil de Facebook las capturas de pantalla de las secciones principales del primer diseño del recorrido del usuario de Planea Perú (Anexo 28). En general, las reacciones a la propuesta fueron positivos y se pudo aplicar la gran mayoría de mejoras. A continuación, los comentarios de mis contactos (se ha hecho énfasis en los que proponen sugerencias y se ha corregido la redacción).

\subsection{Sugerencias en la página principal (Anexo 29)}

- ¿¿La página seria tambien para reservar vuelos u hospedaje? En tal caso podrías agregar un filtro que te permita elegir si quieres reservar actividad, vuelo y/u hospedaje... si no, está perfecto".

- “¿Hay algún filtro de presupuesto? O sea, donde puedas elegir un rango o poner límites".

- "El juego con los colores me parece súper pleasant to the eye y la combinación es estética para mi gusto".

- “Está pajita! La búsqueda avanzada más arriba o más grande para que se note al toque. Si es tu página principal y hay más de un destino, ¿entonces imagino que las imágenes hacen loop? Si es así, deberías agregar una gráfica de puntitos o barritas para que se entienda que hay más contenido a la derecha (o flechas)".

- “Está genial. ¿Hay versión responsive?”

- “iLa sección donde puedes elegir el viaje debería tener más protagonismo! Poniéndola al medio o agrandándola un poco".

- "El buscador debería tener más peso y quizá contar con una sección de paquetes favoritos o más seleccionados".

- "La maleta me parece muy grande y no sé si lo pondría en esa caja de otro color. ¡Linda la idea de la web! Éxitos”.

- "El entorno me parece muy amable y muy intuitivo. Me parece que funcionará bastante bien. Podría mejorar el logo". 


\subsection{Sugerencias en la parte inferior de la página principal (Anexo 30)}

- “Una sugerencia respecto al texto: quizá como es deporte de riesgo, deberías modificar el copy, pero me encanta la idea de sugerir estas actividades porque al redirigirlos a los sites también es recomendarles una agencia segura".

- “Está paja!”

- "El texto podría salir sobre la foto".

\subsection{Sugerencias en la página de propuestas (Anexo 31)}

- "Podrías agregar una pequeña descripción que aparezca cuando pasas el cursor por encima".

- "Me gusta que sean propuestas. Sería la voz que también puedan ser más específicas, como ruta para juergueros, para los que aman la gastronomía, los que adoran el café o los lugares sagrados más bonitos del Perú".

- "Sería interesante ver un filtro de presupuesto como hacen en Booking, Despegar o Trivago. No sé si tiene mucho que ver pero muchas personas manejan precios específicos".

\subsection{Sugerencias en la ventana de descripción detallada (Anexo 32)}

- “Todas salen en fondo negro o depende de la actividad?"

- "Qué lindoooo".

- "Podría incluir un teléfono, por lo demás está paja".

- "Agregaría una sección para que la gente que ha ido al lugar deje recomendaciones. Me gusta que tenga las calificaciones".

- "En estos tiempos, todos tienen rede sociales quizá incluir las del lugar para quienes quieran incluso más información".

- "Sería ideal ver una sección de comentarios donde la gente pueda dejar recomendaciones y ver la puntuación”.

\subsection{Sugerencias en la página final (Anexo 33)}

- "Esta es mi parte favorita".

- "Sería chévere que hubiera una opción para sincronizar con calendario de Google".

- “Está súper chévere".

- "Lo del calendario Google líneas arriba me parece un golazo". 


\section{PROPUESTA CONCRETA DE CONTENIDO Video: 3 festividades que no te puedes perder}

Para la propuesta final de contenido, se optó por un video de corta duración sobre tres festividades peruanas que uno debe visitar al menos una vez en su vida. Estamos hablando del carnaval de Cajamarca, la fiesta de la Virgen de Paucartambo en Cusco y la fiesta de la Virgen de la Candelaria en Puno.

Se eligieron imágenes coloridas y vistosas para capturar al ojo humano que actualmente está muy expuesto a diversos estímulos. Por esta misma razón es que se definió que el video durara menos de dos minutos.

Lo interesante de esta pieza es que funciona tanto en silencio como con sonido, aunque esta última opción permite ver los clips al ritmo de la música agradable y escuchar la siguiente locución: El Perú: tierra de color, alegría y música. Un país donde criaturas míticas bailan en las calles junto a vírgenes y santos. Y donde bailamos tan alto en las montañas que casi tocamos el cielo. Sé parte de la alegría ancestral que las fiestas y celebraciones de nuestro país te pueden brindar. Usa Planea Perú, agenda tu viaje perfecto y únete a nuestra fiesta. Planea Perú. Un viaje a tu medida.

Con esa voz en off no solo se invita a ingresar al portal, sino a ir a conocer cómo se viven las tres festividades. La información es sobre todo visual, pero el video proporciona las fechas y nombres completos de cada uno para que el usuario averigüe más acerca de las tres actividades desde el mismo portal.

Es así que en un poco más de minuto y medio no se pierde la atención del usuario y más bien se motiva a viajar. 


\section{REFERENCIAS}

Adams, R. L. (29 de marzo, 2016). Top Travel Websites For Planning Your Next Adventure. Nueva York: Forbes.

(https://www.forbes.com/sites/robertadams/2016/03/29/the-worlds-best-travelwebsites/\#321bcbac70a7)

Conoce las preferencias del turista digital peruano: destinos, alojamiento y estadías [INFORME] (8 de agosto, 2018). Lima: Portal de Turismo.

(http://www.portaldeturismo.pe/noticia/conoce-las-preferencias-del-turista-digitalperuano-destinos-alojamiento-y-estadias-informe-)

Demanda turística del corporativo peruano crece 7,5\% este año [INFORME] (10 de agosto, 2018). Lima: Portal de Turismo.

(http://www.portaldeturismo.pe/noticia/demanda-turistica-del-corporativo-peruanocrece-7-5-este-ano-informe-)

Ley Mulder: Aprueban polémica prohibición de la publicidad estatal (28 de febrero, 2018). Lima: El Comercio. (https://elcomercio.pe/politica/ley-mulder-apruebancuestionado-proyecto-prohibir-publicidad-estatal-noticia-500903)

Transporte aéreo nacional creció $12.8 \%$ en primer trimestre [Ranking de aerolíneas] (15 de mayo, 2018). Lima: Portal de Turismo.

(http://www.portaldeturismo.pe/noticia/transporte-aereo-nacional-crecio-12-8-enprimer-trimestre-ranking-de-aerolineas-)

Widen, S. (31 de mayo, 2018). Five Best Practices For Travel Tourism Websites. Nueva York: Forbes.

(https://www.forbes.com/sites/forbesagencycouncil/2018/05/31/five-best-practices-fortravel-tourism-websites/\#1f2be2174080) 